\title{
Por que no Papel é Mais Fácil? O Que Fazemos e - Que Falamos que Fazemos no Projeto Político- Pedagógico de um Curso de Graduação: Reflexões sobre o Curso de Fonoaudiologia da FOB-USP
}

\author{
Simone Aparecida Lopes-Herrera ${ }^{1 *}$, Giédre Berretin-Felix ${ }^{1}$, Angelica Bicudo² \\ 'Departamento de Fonoaudiologia da Faculdade de Odontologia de Bauru (FOB) da Universidade de São Paulo \\ 2Departamento de Clínica Médica da Universidade Estadual de Campinas
}

* Autor para correspondência: lopesimone@usp.br

\section{RESUMO}

O projeto político-pedagógico (PPP) de um curso de graduação precisa ser realmente abraçado no contexto acadêmico a que pertence, sendo pedagógico por discutir o processo de formação e politico por tratar dos fins e valores referentes da universidade. Análises pontuais de PPP auxiliam não somente a instituição analisada, como também outras instituições de ensino em reflexões e ações sobre formação profissional. No entanto, fica sempre a pergunta: o que fazemos em nosso curso é o que realmente está escrito e descrito nas vias documentais? $\mathrm{O}$ que está escrito reflete o perfil do egresso que postulamos? O objetivo deste trabalho foi analisar se as características atuais do PPP do Curso de Fonoaudiologia da Faculdade de Odontologia de Bauru (FOB), da Universidade de São Paulo (USP) refletem o perfil do egresso a que se deseja formar e o que efetivamente é colocado em prática no curso. Os resultados apresentados são o recorte de um dos itens de pesquisa qualitativa (Tese de Livre-Docência) realizada por entrevistas semiestruturadas com membros da Comissão de Coordenação de Curso (CoC-Fono), Chefia de Departamento e Comissão de Graduação da Unidade; as entrevistas foram gravadas, transcritas e submetidas à análise de fidedignidade intercodificadores. A análise de conteúdos temáticos-categoriais foi realizada via software NVivo, sendo que a categoria final a ser aqui apresentada é a de características do PPP atual (perfil de formação, base teórica, pontos fortes e fracos, coerência da estrutura curricular, nível de aceitação e conhecimento da comunidade acadêmica). A análise realizada identificou que a construção do PPP foi um processo coletivo e longo, mas necessário como dessensibilização da comunidade acadêmica. O perfil do egresso é generalista, embora haja contraditoriamente grande foco nas especialidades, o que reflete que o documento formal mostra mais o que é postulado pelas Diretrizes Curriculares Nacionais do que o realmente desenvolvido na prática. Há definição dos eixos principais, utilização de novas metodologias e tentativas de integração de disciplinas pontuais, embora ainda apresentadas em estrutura de grade, com alta carga horária - o que entra em conflito com a formação de um profissional reflexivo e flexível postulado no PPP. Notou-se bom nível de aceitação e satisfação, apesar de docentes e discentes demonstrarem baixo nível de conhecimento sobre o PPP - o que parece contraditório, pois não se aprova ou reprova aquilo que não se conhece. Perspectivas futuras se relacionam à nova proposta de reformulação, com expectativa quanto ao método modular e tutorial para contemplar as necessidades do curso, a sociedade atual e o perfil do aluno ingressante, ensejando as atuais propostas da USP para o ensino de graduação.

Palavras-chave: Fonoaudiologia; Educação Médica; Ensino Superior; Currículo; Projeto Pedagógico.

\begin{abstract}
The undergraduation courses in Brazil requires a Political-Pedagogical Project (PPP) as collective construction of an institutional project that is pedagogical, for addressing the professional formation process, and political, for addressing purposes and values regarding the role of the university in the critical analysis and social transformation. Specific analyzes of institutions that developed or modified such project assist not only the institution analyzed, but also other educational institutions as well as the entire professional field by providing reflections and actions on professional formation. The aim was analyze the process of elaboration and implementation of the PPP of the Speech Language Pathology and Audiology Course (SLPA) of the Bauru School of Dentistry, University of São Paulo (FOB-USP). Qualitative research conducted by means of semi-structured interviews with members of the SLPA Course Coordinating Committee (CoC-Fono), the head of the SLPA Department and Undergraduate Commission regarding the PPP's preparation and implementation. The twelve interviews conducted were recorded, transcribed and analyzed for intercoder reliability. The content categorical-thematic analysis was performed via NVivo software and the final emergent categories were: (1) construction of PPP (creation and
\end{abstract}


implementation of the CoC-Fono, elaboration decision, institutional support, conducting the process, adopted strategies, hindering and facilitating factors, professors and students participation); (2) characteristics of the current PPP (formation profile, theoretical basis, strengths and weaknesses, coherence of curriculum, acceptance level, knowledge and satisfaction of the academic community) and (3) future perspectives (effective changes, proposals of continuity and expectations). he analysis identified that the PPP's construction began with the creation of the CoC-Fono - a document with the SLPA Course guideline already existed, however, it could not be characterized as a PPP. This fact as well as the legal and institutional requirements, led to the decision of elaborating a PPP, this being conducted by the CoC-Fono, with strong institutional support and variable involvement of the academic community. The later was due to initial resistance and limited participation resulting from high demand of other activities in the university. The strategies adopted were discussion forums, meetings, workshops, seminars and university pedagogy courses as well as professors and students evaluation of the course's curricula. This process was described as being long, but necessary for desensitization of the academic community. The alumnus profile is generalist, however, there is a strong focus on specialties. There is a definition of the main axes, the use of new methods and attempts to integrate disciplines, although still presented in a curriculum structure with a high workload. There was a good level of acceptance and satisfaction, although professors and students demonstrate low level of knowledge about the PPP. Future perspectives relate to the new proposal of PPP's revision, with expectations regarding the incorporation of modular and tutorial methods to accommodate the needs of the SLPA course, the society and the profile of incoming students in line with the aspirations of academic and institutional community in an integrated manner while maintaining the level of excellence at USP.

Keywords: Speech Language Pathology and Audiology; Higher Education; Curriculum; Education Project.

\section{Introdução}

A pesquisa que deu origem a este trabalho (LOPES-HERRERA, 2014) teve por objetivo analisar o processo de elaboração e implantação do Projeto Político-Pedagógico (PPP) do Curso de Fonoaudiologia da Faculdade de Odontologia de Bauru (FOB), da Universidade de São Paulo (USP). No entanto, as questões norteadoras do excerto da pesquisa aqui exposto foram: a) No processo de elaboração do PPP do referido curso de graduação, como se vivenciou a relação entre as normas legais em âmbito nacional e institucional?; b) Como ficou definida a identidade do fonoaudiólogo no PPP? E os conteúdos propostos se adequam ao perfil do egresso desejado?; c) A estrutura curricular, as ementas e planos de ensino das disciplinas e os conteúdos efetivamente ministrados contemplam os princípios norteadores e o perfil do egresso postulado no PPP?

Braid, Machado e Aranha (2012), em estudo em que levantaram o estado da arte das pesquisas sobre currículo em cursos de formação de profissionais da área da saúde no Brasil, observaram um contexto de mudanças nas instituições de ensino superior (IES) brasileiras nos últimos dez anos fomentado pelas Diretrizes Curriculares Nacionais para os Cursos de Graduação, o que sinaliza a preocupação das IES sobre essa questão. No entanto, o volume de pesquisas tem sido maior na área da Medicina e Enfermagem, havendo pouca referência ao processo de implantação de currículos integrados em outros cursos, situação que chama a atenção, considerando ser fato, desde o início da década de 2000, a necessidade de esse modelo de currículo ser implantado em cursos na área da saúde.

Refletindo sobre os resultados encontrados, Braid, Machado e Aranha (2012) enfatizaram duas características: a incipiência dos estudos sobre os processos de elaboração ou reelaboração de projetos político-pedagógicos como norteadores dos cursos de graduação desenvolvidos dentro de centros de ciências da saúde; e o fato de que - embora toda inovação curricular inverta a lógica do processo ensino-aprendizagem - ela não tenha provocado um volume maior de estudos sobre a formação docente, considerando o professor como um dos principais atores sociais no processo de construção, implantação e implementação de novas propostas curriculares.

Experiências de mudança de currículo, no âmbito de um novo projeto político pedagógico, exigem uma avaliação do processo que possibilite refletir sobre as perspectivas da formação 
profissional. Feuerwerker (2007) ressalta ser esta uma demanda de pesquisa, destacada por analistas do campo da Educação em Saúde que afirmam haver pouca sistematização do conhecimento produzido nas experiências inovadoras nessa área e ainda menores iniciativas de avaliação que abordem a complexidade dos processos.

Dessa forma, investigações na área são prementes, principalmente na Fonoaudiologia, que - sendo uma profissão da área da saúde, de caráter interdisciplinar, com cada vez maior inserção em contextos da saúde coletiva nacional, e, ao mesmo tempo, sendo uma ciência de recente reconhecimento, levando-se em conta o histórico da Educação Superior no país - necessita de estudos que descrevam, avaliem e validem suas iniciativas na formação do profissional fonoaudiólogo.

\section{Desenvolvimento}

$\mathrm{O}$ presente estudo foi desenvolvido junto ao Departamento de Fonoaudiologia da FOB-USP. A seleção da amostra de participantes foi realizada de forma intencional, pelo critério de conveniência, conforme proposto por Silverman (2010). Foram convidados a participar voluntariamente desta pesquisa integrantes da comunidade acadêmica que se envolveram de forma direta no processo de elaboração e implementação do projeto político pedagógico (PPP) do Curso de Graduação em Fonoaudiologia, a saber: membros titulares da Comissão de Coordenação do Curso - CoC-Fono (docentes e discentes), Chefia de Departamento, Presidente(s) da Comissão de
Graduação (CG) da Unidade e Representante Docente do Conselho de Departamento na CG em exercício no período de 23 de setembro de 2009 a 22 de setembro de 2011, num total de quinze pessoas. Ao final, foram realizadas doze entrevistas. Por questões éticas, preservou-se a identidade dos participantes. Todos os participantes assinaram o termo de consentimento livre e esclarecido, e os procedimentos da pesquisa foram submetidos ao Comitê de Ética em Pesquisa da FOB-USP e aprovados sob parecer número 321.959, de 26 de junho de 2013.

Nesta pesquisa, optou-se pelo método qualitativo (MINAYO, 2006), que é a abordagem que melhor se adequa a investigações de grupos, relações e análise de discursos. $\mathrm{O}$ instrumento adotado foi o roteiro de entrevista semiestruturada e as perguntas nele contidas levaram em consideração as perguntas norteadoras da pesquisa. As entrevistas foram conduzidas por uma auxiliar de pesquisa previamente treinada. Logo após sua realização, cada entrevista era ouvida na íntegra pela pesquisadora (primeiro momento de escuta). Em seguida, as entrevistas eram transcritas (transposição das informações orais em escritas), o que representou uma pré-análise do material (MANZINI, 2008) - segundo momento de escuta. Nesta pesquisa, foram anotadas, neste momento, as palavras e expressões por estrutura de relevância, conforme indicado por Bardin (2010): por repetição, por ênfase e pelo inusitado.

A seguir, será apresentada uma síntese da coleta de dados, em que estão indicadas as diferentes fases da coleta de dados desta pesquisa (Figura 1).

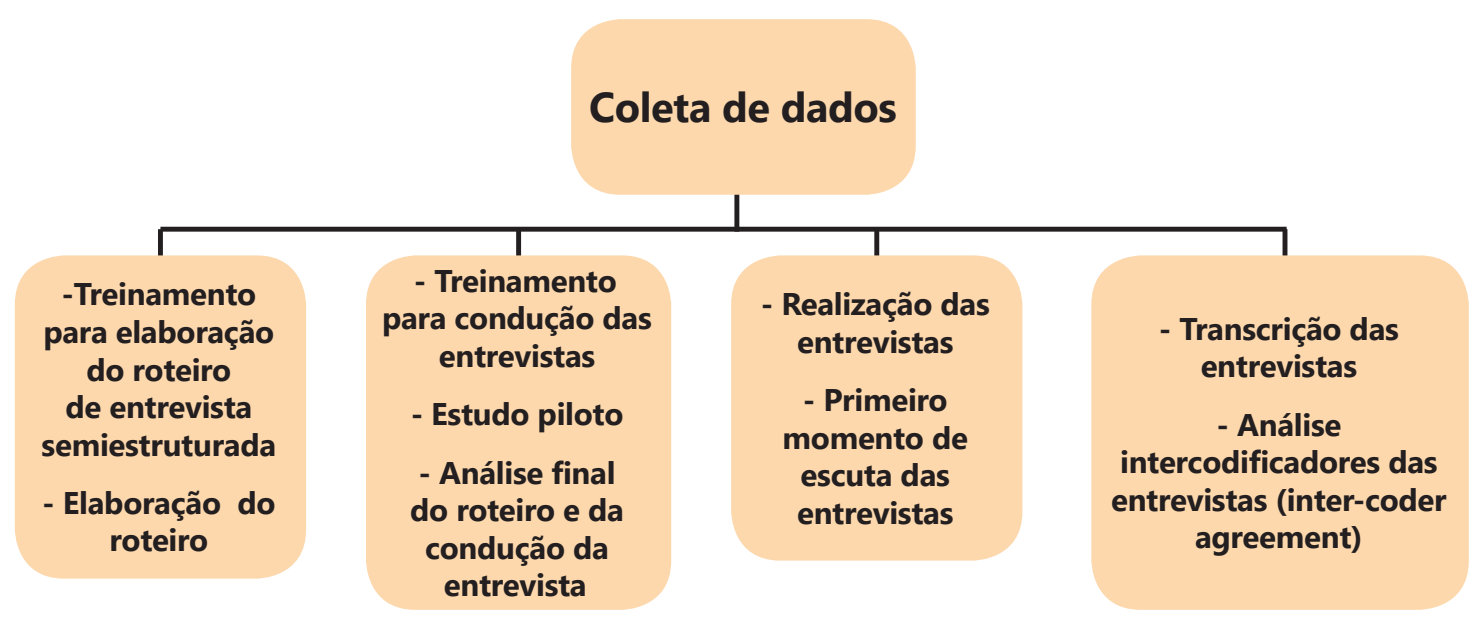

Figura 1 - Síntese da coleta de dados. 
O material derivado das transcrições foi analisado pelos princípios da análise de conteúdo temático-categorial (MINAYO, 2006; OLIVEIRA, 2008; BARDIN, 2010), que é uma técnica da área das comunicações que visa a obter indicadores (quantitativos ou não) que permitam chegar ao conhecimento das condições de produção e de recepção do material analisado, por meio de procedimentos sistemáticos e objetivos, de descrição e categorização dos conteúdos das mensagens. Justifica-se a relevância do enfoque qualitativo que a análise de conteúdo permite pelo fato de que o objetivo não é produzir generalizações do tipo estatístico, mas sim propor uma interpretação crítica do material coletado. Nesse sentido, é apresentada a Figura 2, como síntese da análise de dados, em que estão indicadas as fases realizadas na pesquisa.

Na etapa de exploração do material, a pesquisadora utilizou o software NVivo 10 (NVivo 10 for Windows, QSR International) ${ }^{1}$. As ferramentas computacionais em pesquisa qualitativa são úteis quando há grande volume de dados e possuem funcionalidades como: facilidades para codificação dos dados, gerenciamento das fontes de informação, mecanismos de busca, facilidades para categorização durante o processo de codificação, entre outras; no entanto, ainda é baixo o volume de pesquisas qualitativas que usam algum tipo de software de apoio (LAGE, 2011). No caso da pesquisa aqui apresentada, o tratamento de dados no NVivo foi realizado em três etapas, conforme apresentado na Figura 3, baseado em Lage (2011).

Conforme recomendado por pesquisadores na área de pesquisa qualitativa com uso de softwares (SILVERMAN, 2010; LAGE, 2011), a pesquisadora também realizou a categorização final manualmente, como já exposto no item anterior, levando em consideração seus objetivos de pesquisa e hipóteses levantadas, e confrontou suas categorias com as originadas pelo software, para gerar a categorização final. Para certificação das categorias finais, a pesquisadora realizou o cálculo de frequência de palavras, com geração de nuvem de palavras e mapa de árvore de cada nó e subnó, confrontando o dado com a primeira análise de frequência de palavras de forma exaustiva pela pesquisadora e por uma outra pesquisadora auxiliar treinada no uso do software e contratada com esse propósito (estando esse profissional envolvido no projeto desde a elaboração do roteiro de entrevista até a conferência das transcrições).

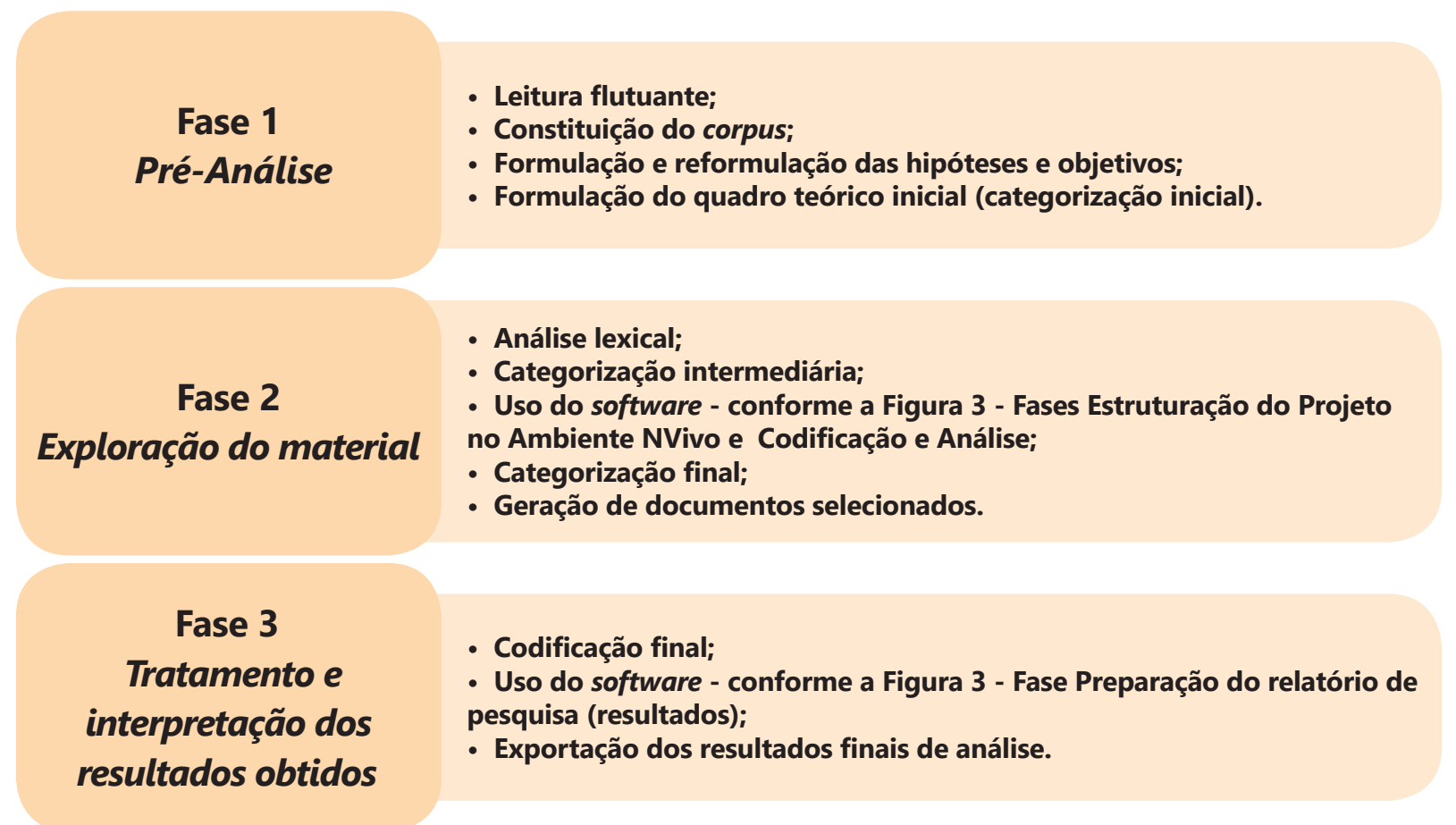

Figura 2 - Síntese da análise de dados. 

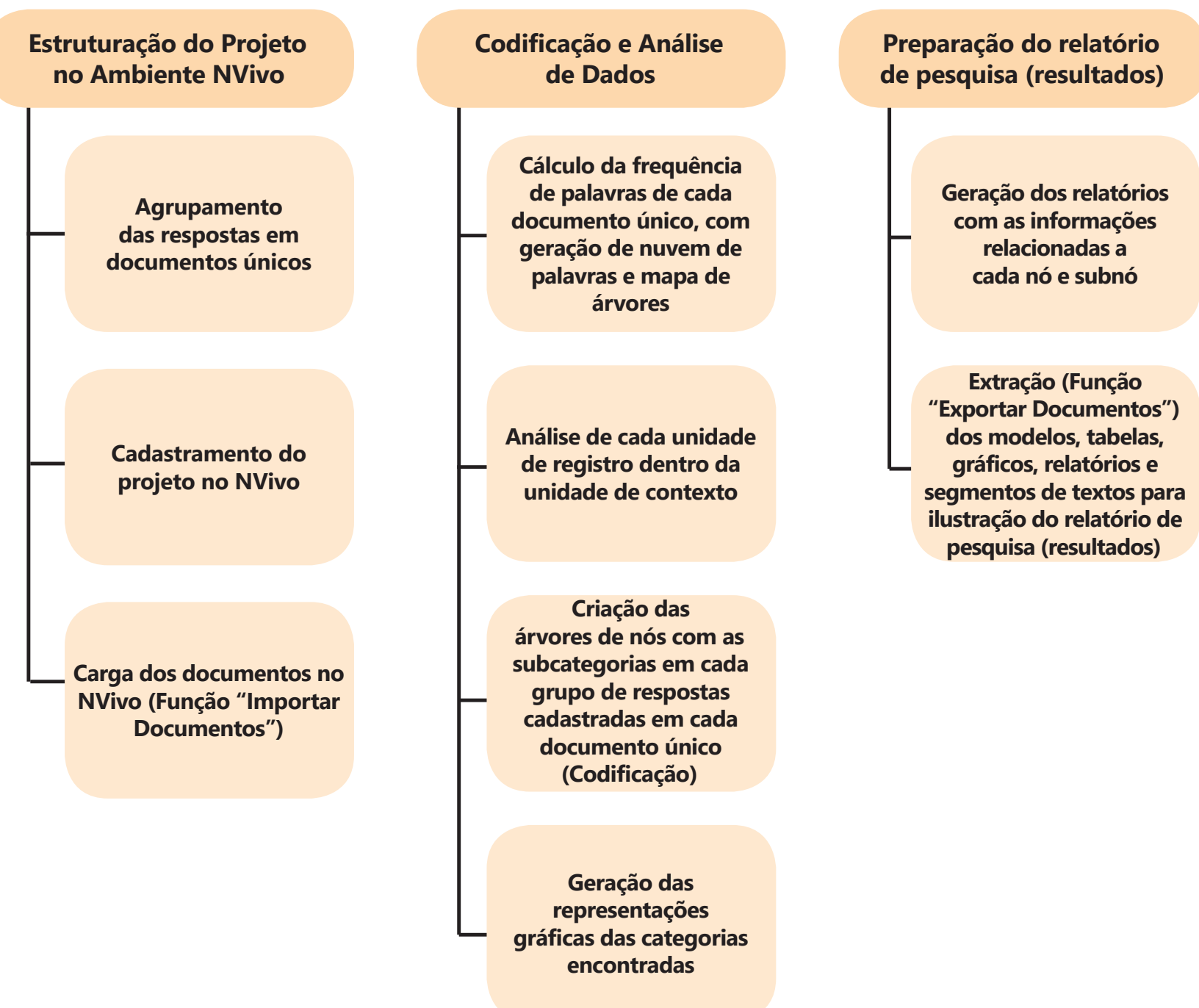

Figura 3 - Processo de análise de dados da pesquisa no software NVivo.

\section{Resultados e Discussão}

O material transcrito e analisado gerou 253 páginas, sendo que cada entrevista resultou em uma média de 21 páginas (variando de, no mínimo, onze a, no máximo, 37 páginas). Nas três principais categorias de análise final (nós principais), foi armazenado um total de 2442 referências. Cada referência indica a quantidade de ocorrências, isto é, quantos fragmentos de documentos foram codificados naquela determinada categoria (Tabela 1).

Neste artigo serão apresentados os dados da categoria Características do PPP atual, que foi a categoria que mais apresentou referências (1321). A Figura 4 mostra a nuvem de palavras com as palavras mais citadas nas referências realizadas nesta categoria.

Todos os entrevistados definiram o perfil de formação do aluno de graduação do Curso de
Fonoaudiologia da FOB-USP como um perfil generalista, mas há críticas e reflexões explicitadas sobre se realmente essa formação é produzida, se ela é efetiva, se o fato de o curso tentar contemplar todas as áreas de formação de um fonoaudiólogo garante que o profissional formado seja generalista e se o aluno consegue fazer a integração de todos os conteúdos ministrados na tentativa de formar um generalista.

Realmente, bom, nosso intuito é formar o generalista, né?! Sim, acho que nós temos formado, né, eu acho que sim, ele sai um pouco, é generalista [...] mas, ao mesmo tempo que temos o profissional generalista, temos as especialidades, mas eu não sei se nós estamos formando o generalista na hora que ele tiver lá na clínica dele e ele tiver um 


\begin{tabular}{|l|l|}
\hline Categorias principais & Quantidade de ocorrências (Referências) \\
\hline Processo de construção do PPP & 1045 \\
\hline Características do PPP atual & 1321 \\
\hline Perspectivas futuras & 76 \\
\hline Total & 2442 \\
\hline
\end{tabular}

Tabela 1 - Quantidade de Ocorrências por Categoria Principal. PPP: Projeto Político-Pedagógico.

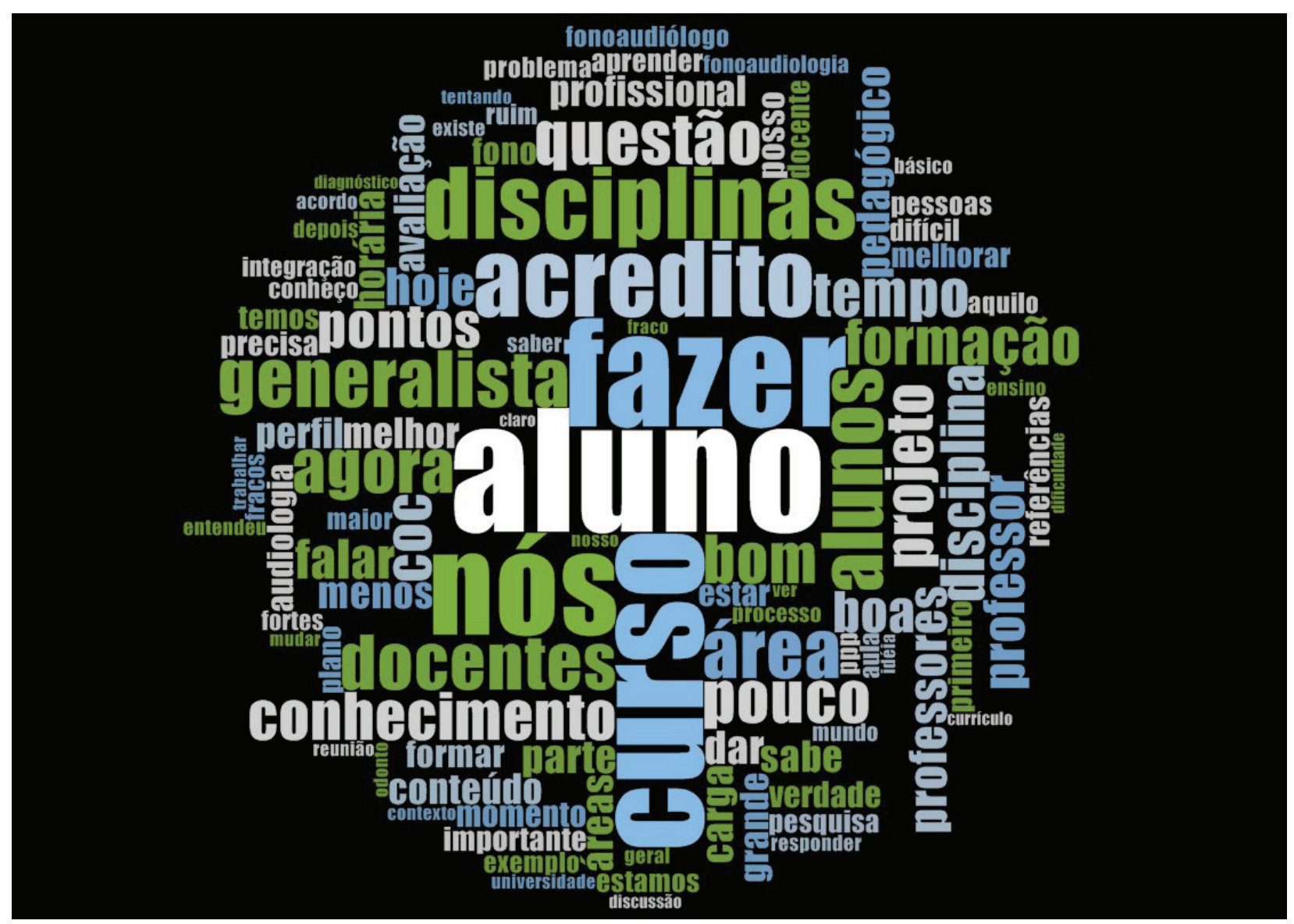

Figura 4 - Nuvem de palavras da categoria principal "Características do PPP atual".

caso onde ele tem todas as patologias, se ele consegue dar conta. Entendeu, por exemplo, se você tem lá na sua clínica um paciente que tem alteração de voz, gagueira e problemas com linguagem escrita, se você dá conta de atender, é generalista [...] aqui é cada um na especialidade e alguma coisa a gente tá falhando porque, às vezes, as especialidades depois não se encontram no curso, é tudo separado, entendeu? (E6)

Então, pra mim essa frase "a formação do profissional generalista" é uma grande discussão, ele é generalista? Ele é, porque ele vê tudo da Fonoaudiologia veja bem [...]. Então ele é generalista, se você falar que ele é generalista, no sentido de que ele viu tudo que existe na Fonoaudiologia, ele é; agora ele é um profissional que consegue sentar na frente de um paciente e trazer todo aquele conteúdo e ver o todo? Isso eu acho que nós ainda não estamos conseguindo fazer [...]. Então eu acredito que este seja o problema do nosso curso e, pra mim, falta no mínimo essa interdisciplinaridade. (E5) 
Eu não sei te dizer quais foram as palavras exatas, mas acaba ficando assim generalista, ter um caráter holístico, eu já ouvi algumas vezes, mas eu sinceramente não lembro, isso é uma das coisas que pra mim ainda são distantes; do ponto de vista pedagógico, tem muitas definições de ser generalista, holístico, mas acaba sendo muito genérico, é uma coisa muito bonitinha mas eu acho pouco prático, então eu não saberia responder a sua pergunta e deveria saber responder. Este é o reflexo dessa distância grande desse lado mais teórico e o lado realmente prático, de onde a gente tem mais conhecimento e um pouco mais de habilidade. (E4)

Não, na verdade eu acho que talvez exista uma diferença entre o que é realmente formado e o projeto, mas eu acho que - dentro das discussões - o que se objetivava, isto está compreendido nas definições que foram colocadas, agora a distância entre o que está no papel e o que realmente seria, eu não sei, até por não acompanhar, só acompanho no primeiro ano e não tenho o conhecimento a partir daí, é uma pergunta que eu também não sei responder, mas talvez a diferença seja entre a ideia e a formação efetiva. (E2)

O projeto pedagógico foi quem pressentiu o fonoaudiólogo generalista e, na prática, a construção desse fonoaudiólogo generalista ainda não é muito clara. Porque a gente, sem o conhecimento fragmentado pelas diferentes especialidades, de uma forma que não é integrada, falta integração pra ele poder se tornar generalista, porque ele nem é especialista nem generalista. Então falta integração em ter os conhecimentos todos e mais capacidade de tomada de decisão e escolha na hora de definir o procedimento de avaliação e intervenção. (E10)

O perfil generalista é amplamente perseguido nos projetos político-pedagógicos de grande parte das profissões de Saúde, como apontado em inúmeros trabalhos científicos (BECK et al., 2003; FREITAS; GUEDES; SILVA, 2003; OLIVEIRA et al., 2003; SANTOS, 2006; SIGNORELLI et al., 2010; PÜSCHEL, 2011), visto que se entende que generalistas são profissionais que devem incorporar à sua bagagem clínica o saber epidemiológico, de educação em saúde, de trabalho em grupo, de gestão e conhecimentos que os ajudem na articulação de projetos de intervenção individual e coletiva em suas áreas de saberes. Portanto, é importante que tenham sólidos conhecimentos sobre grupalidade, relações humanas, iniciativa, dinamismo e capacidade de trabalho em equipe interdisciplinar. $\mathrm{Na}$ formação do generalista, há a necessidade de um conhecimento mais global e menos específico. Isto significa que disciplinas mais voltadas para áreas de especialização da profissão não precisam fazer parte do elenco de disciplinas mais gerais (SANTOS, 2006).

Em processos de elaboração de PPP, é comum haver a discussão sobre o perfil do profissional que se deseja formar, como o ocorrido aqui na pesquisa apresentada. Carvalho Filho (2011) aponta que, no contexto da educação médica, as diretrizes da formação profissional, no sentido das definições acerca de "que médico formar", constituem uma das polêmicas centrais hoje no Brasil, polarizando posições entre os que defendem uma formação cientificista e voltada para a especialização e os que proclamam uma formação de caráter comunitário, direcionada para o trabalho no Sistema Único de Saúde. Na pesquisa aqui apresentada, há relatos que ressaltam a questão de o curso não ter uma identidade e de a formação na Unidade privilegiar, por vezes, a formação para pesquisa, sendo este um perfil da FOB-USP.

$\mathrm{Eu}$ acho que tem ajustes a serem feitos, ainda não, não existe uma identidade, assim, uma identificação exata, entendeu? Isso era uma das missões que a gente tinha em relação ao PPP, era pra tornar o perfil realmente assim, o que está escrito lá, se realmente é o perfil que a gente está formando. Eu diria pra você que ainda tem, digamos que ele está assim, olha, se tivesse que fazer uma representação, ele não está assim, círculo sobre círculo. Eu diria que ele tem círculo, tem muita coisa que confirma e tem algumas coisas que ainda precisam ser vistas, do que está escrito. (E6) 
Apesar de eu não estar dentro do curso de Fono, eu não sei [...]. Veja, o PPP diz que é um generalista, tá, e eu acredito que seja generalista sim, acho que vocês têm uma noção muito boa num todo embasado no documento científico de todas as áreas. Vocês têm uma formação muito diferenciada, tá, pra mim muito mais que generalista então, esse é o perfil. Agora é um estudante que, no meu modo de ver, é bastante voltado pra, pra investigação. Eu não vou usar a palavra pesquisa, mas a pesquisa pra essa investigação científica é uma coisa que é muito cobrada de todo mundo, durante os quatro anos de curso, como se isso fosse uma obrigação do aluno. (E8)

Então, essa é uma opinião pessoal, eu tenho algumas restrições a essa, esse exagero nesse cientificismo, né, nessa busca por "papers", né, mas eu sempre vi isso, não é só o aluno de Fono, o aluno de Odonto também, se dá muita importância pra essa bolsa de iniciação científica, pra essa participação na iniciação científica. Isso é muito bom, muito bom desde que, realmente, a gente discuta ciência, esse é que o problema [...] mas se a gente pegar uma peneira mesmo e der uma boa peneirada em tudo isso que se produz, a gente vai ver que tem muito pouco de ciências em tudo isso. Então, tem muito mais de publicação do que ciência, mas essa é a minha visão pessoal e tal, mas eu acho que é um generalista. Generalista e com um holofote na direção na pesquisa. (E7)

A questão da ausência de uma identidade profissional também é citada na pesquisa de Oliveira (2011). Nela se afirmou que, em termos da identidade do pedagogo, a manutenção dos aspectos gerais transferidos do currículo antigo para o atual pressupõe a ênfase na formação do pedagogo especialista, com perfil em pesquisa, a despeito da significativa redução de carga horária nas chamadas áreas de aprofundamento. Cunha (2006) expõe que a formação do professor universitário tem sido entendida, por força da tradição e ratificada pela legislação, como pertinente quase que exclusivamente aos saberes do conteúdo de ensino.
Espera-se que o professor seja, cada vez mais, especialista em sua área, tendo-se apropriado, com o concurso da pós-graduação stricto sensu, do conhecimento legitimado academicamente no seu campo científico, sendo que o domínio do conteúdo, por sua vez, deve ser alicerçado nas atividades de pesquisa que garantam a capacidade potencial de produção do conhecimento.

De forma geral, os entrevistados relataram ser a base teórica e a estrutura curricular boas, mas com ressalvas específicas quanto à falta de integração curricular e à necessidade de constante mudança do PPP para adequação ao perfil do aluno.

Acho que todo plano é... nunca está acabado, né?, tem sempre de estar atualizado de acordo com as necessidades da profissão. Eu acho que, se ele conseguir fomentar a integração, seria o melhor, acho que a grande dificuldade é que a integração exige mais do que o papel. (E9)

Dentro do que eu conheci, que não é a parte inicial, eu acho que é muito boa e, até pela experiência que a gente tem de algo parecido, a ideia é muito boa e a execução prática tem se mostrado não ideal; ainda tem muita coisa pra ser ajustada por muito tempo, uma diretriz um pouco mais direcionada à integração e, mesmo achando que a participação das disciplinas básicas ficou um pouco deslocada, porque no começo no primeiro ano é uma fase em que tudo é diferente, tem a fase de adaptação, mas eu acho que foi funcional. (E4)

Acredito que boa, porque agora a gente vai passar por uma reforma curricular também e aí isso também com certeza vai ter, ter influências, mas acredito que parte acho que dentro daquilo que foi proposto naquele momento, pra aquela situação, sim. Bom, acho que é o que tá sendo feito, né?, tá sendo tentado, né?, na verdade é tornar o curso um pouco mais dinâmico, é oferecer mais possibilidades pro aluno e um ensino mais integrado entre as disciplinas, né? (E5)

Eu acho que o plano político-pedagógico ele sempre tem uma ideia de ser bom e..., é bom, mas 
eu acho que tem que estar em constante modificação, porque é constante a modificação no mercado de trabalho, então eu acredito que talvez o plano político pedagógico talvez mude, pelo perfil hoje de nossos alunos, que eles não estão mais para aprender lá fora, não é só atender num consultório, na clínica. Hoje existe muito saúde pública, então instituições, então talvez o nosso plano político pedagógico tenha que ser mexido nesse sentido, não se pensar num aluno que sai daqui com o objetivo de sair um fonoaudiólogo clínico, eu acho que ele vai ter que enfocar mais o lado mais SUS, mais para a parte de atenção básica. (E11)

Na verdade, eu acho que ela, mais no mesmo contexto geral, tá! Eu acho que ela é boa quando se vê o produto final, o fonoaudiólogo que se formou ele é competitivo, ele é aquele que atende ao mercado, que não é muito grande, mas ele atende ao mercado, ele é um aluno de graduação que sai sabendo que o conhecimento da graduação não é totalmente suficiente, tem que se especializar e eventualmente fazer pós, mestrado e doutorado e, eventualmente, até ir para o exterior, aqueles que pretendem seguir carreira universitária e outros estão preocupados em ser proficientes em inglês e outros estão ansiosos por ter uma bolsa, essa bolsa na graduação, ela é praticamente um dos pré-requisitos para o seu aceite na pós, então eu acho que o curso atingiu seus objetivos. (E3)

A respeito da inter-relação de disciplinas, a questão da interdisciplinaridade é colocada por Carvalho Filho (2011) como um dos fundamentos da formação médica propugnada pelo novo currículo do curso por ele analisado. Constitui uma das suas questões fundantes, mas carece de melhor explicitação conceitual e metodológica nas visões de professores e alunos. De fato, a interdisciplinaridade contrapõe-se a uma das marcas, por excelência, do ensino acadêmico: a divisão do currículo em disciplinas, assumidas por especialistas que se reconhecem como os legítimos detentores do saber em cada área disciplinar.
Em síntese, na pesquisa aqui apresentada, os pontos fortes da estrutura curricular apontados pelos entrevistados foram: uma boa base, ainda que com ressalvas quanto à falta de integração; a existência de uma matriz curricular norteadora após a elaboração do PPP; tentativas pontuais de integração que vêm sendo realizadas como um ponto inicial para futura integração curricular; consideração feita às demandas sociais e à formação do aluno em todas as áreas da Fonoaudiologia.

De maneira geral, os pontos fracos citados foram a falta de envolvimento e de adesão de todos os docentes ao processo de mudança, ao acompanhamento de egressos, a falta de integração entre disciplinas; mas o ponto mais ressaltado foi a constituição da estrutura ainda ser em grade de disciplinas, o que geraria uma falha na formação de um aluno mais crítico, de um cidadão e não somente de um bom profissional:

Isso daí acho que realmente são os professores, né?, aqueles que acham que... é... que o curso tá bom, é cinco estrelas, que não precisa mudar [...]. Então, às vezes ele não entende que não é porque está bom que não pode melhorar. (E9)

Os pontos fracos, o que talvez acredito que envolve de novo essa questão, é o não entendimento ou pouco envolvimento de alguns docentes, né?, do desentendimento da construção que a gente tá fazendo de não entender e vir prejudicar a implantação disso. (E4)

Eu acho que a gente, ainda hoje, tem essa fragmentação pelas disciplinas e que eu acho que a $\mathrm{CoC}$ atualmente está tentando, né?, está buscando rever, é a notícia que eu estou tendo, né?! Não estou mais nas reuniões, mas vem, vem aí, vem aí pros próximos capítulos, próximos anos, uma grande reforma buscando uma integração maior entre as disciplinas; então assim, isso é necessário, porque do jeito que está hoje ainda está muito fragmentado. (E7)

[...] Como eu já falei, a gente tá tentando trabalhar, nós queremos alunos que façam pesquisa, 
mas não tem tempo; [...] eu gostaria de alunos mais críticos, né?, mas formar um cidadão e não só um excelente profissional, então eu gostaria de ter disciplinas assim mais genéricas, que permitissem uma reflexão crítica do todo, mas isso eu acredito, mas não participei da última reunião, mas eu acredito que seja uma proposta, não sei se é exatamente isso, mas vai ter que ter; se você quer montar uma nova proposta pensando na transdisciplinaridade, é... nós vamos ter que montar, formar um aluno mais crítico, mais independente no aprender, senão ele não vai conseguir sobreviver nesse novo mundo, né? (E5)

Então eu acho que é isso que temos que repensar, e um ponto fraco, que não é do projeto pedagógico e não sei se eu posso chamar de fraco, mas o processo de avaliação do aluno, eu acredito que a avaliação de cada professor, não questiono a minha avaliação nem dos colegas, nada disso, mas eu acredito que um preparo maior para nós docentes para fazermos a avaliação. Fico tranquila em falar isso porque eu tenho vinte e poucos anos de carreira docente e, de tudo que eu faço, o mais diff'cil é avaliar, mas às vezes teve aluno no quarto ano que eu me questiono como que ele conseguiu passar nessas disciplinas, né? E, falar do ponto fraco, aí desculpa, mas é isso: eu acho que o ponto fraco, a avaliação, então eu sinto assim que, de tudo que eu faço como docente, pra mim o mais difícil é avaliar, né? Esse aluno está preparado para ir para a disciplina da minha colega que vai exigir um conteúdo num nível mais, de uma cobrança maior, né? (E11)

Ponto fraco? Essa grade engessada, a grade engessada que o aluno não tem tempo pra respirar, né? Pouca área verde, porque eles não conseguem, alguns estágios demandam que o aluno vá até $\mathrm{o}$ serviço, por exemplo, precisa ir à escola, precisa discutir o caso com outro profissional daqui, e o aluno não tem tempo pra isso, então isso prejudica o próprio andamento do estágio dele, da formação dele, eu acho que a gente precisa ter uma grade menos engessada, com horário para que o próprio aluno amadureça e se responsabilize pela construção do seu conhecimento. (E12)
Anastasiou (2001) cita que o currículo com organização tradicional reflete o modelo de racionalidade científica, que, na busca de respostas a questões cada vez mais específicas, fragmentou o saber constituindo as áreas ou especializações. Portanto, um currículo organizado por grades não é condizente com um curso que afirma ser o perfil do aluno que quer formar um perfil abrangente e generalista, o que deve ser um ponto de reflexão futura do grupo que trabalhou na elaboração do PPP e está trabalhando na futura reforma curricular do Curso de Fonoaudiologia da FOB-USP.

Quanto ao fato de ser citada a falha na formação de um profissional crítico e reflexivo, é importante deixar claro que o processo pedagógico que visa a formar um profissional com este perfil deve estimular, desde uma fase ainda precoce, a formação do ato reflexivo por parte do aluno, desenvolvendo sua capacidade de observação, análise, crítica, autonomia de pensar e de ideias, ampliando os horizontes e tornando-o agente de transformações sociais. A autonomia e a responsabilidade de um futuro profissional dependem de sua capacidade de refletir em e sobre sua ação, sendo que essa capacidade está no âmago do desenvolvimento permanente (ANASTASIOU \& ALVES, 2009; NÓBREGA-THERRIEN et al., 2010). O fato de esta falha já ter sido apontada pelo grupo que trabalhou na elaboração do PPP e que está trabalhando na futura reforma curricular do Curso de Fonoaudiologia da FOB-USP é um avanço no sentido de que ela possa ser superada.

Quanto à coerência entre os planos de ensino das disciplinas existentes atualmente e a estrutura curricular vigente proposta no PPP, os entrevistados relataram que a maioria dos docentes, ao elaborar seus planos de ensino, não consulta o PPP e que a CoC e a CG já estão trabalhando nesse aspecto e devem enfocar ainda mais a conscientização docente sobre isso. Inclusive, foi citada a proposta de que, nos concursos de entrada dos docentes, já deveria ser cobrado conhecimento relativo ao PPP do curso de que o docente está postulando fazer parte.

Eu não sei se cada disciplina parou pra olhar o PPP. Eu acho que as disciplinas não pararam pra 
olhar o que está escrito lá [...] que eu vou formar um fonoaudiólogo generalista, com sólida formação científica e isso e aquilo [...] então, acho que ninguém parou pra enquadrar sua disciplina. (E8)

Agora, agora sim, porque eu percebo que está existindo, a COC ela está tendo uma preocupação mais nesse sentido, entendeu?! Orientando os professores a verificarem suas ementas e estruturar melhor o seu plano de ensino, né?! (E1)

Então, eu até acho que a gente tá caminhando um pouquinho pra isso, eu acho que falta muito, por exemplo, pra nós, não sei os argumentos, né?, talvez tenha o que faz, né?, mas eu acho que tem que ir lá procurar, rever, eu acho que é difícil, mas o que eu percebo aqui, qual é a nossa dificuldade maior? Nós temos as nossas reuniões de colegiado, de conselho, de CG, reunião disso, daquilo, mas não temos nenhuma reunião para discutir, a reunião teria que ser reunião do corpo docente, eu acho que isso deveria estimular mais, participar mais, das disciplinas do outro, não sei. (E3)

O papel, acho que é conscientizar todo mundo [...]. Uma coisa que pudesse fazer, tá?, uma das coisas que todo docente que entrasse no curso que fosse contratado, no concurso pra contratação, o cara tinha que ser sabatinado, não sobre quantos trabalhos publicou, mas sobre o projeto da escola: "Você conhece o curso, o curso fala de quê? Que fonoaudiólogo você vai formar? Que dentista vai formar?". Então, essa é uma coisa que a gente não vê, não dá valor. (E6)

O concurso mesmo poderia fazer um negócio desses, de cobrança, as bancas ao selecionar os docentes, tá?, deveriam fazer isso. Agora, os próprios departamentos, acho que deveriam pegar essas disciplinas e parar um pouco pra pensar, né?, que a gente poderia talvez criar um momento de reflexão sobre o projeto. Será que o conteúdo que eu estou colocando é pertinente? A CoC faz esse trabalho, né? (E9)

\section{Considerações Finais}

De forma geral, para Feuerwerker (2002) e Souza (2010), nos currículos existe uma diferença entre o que se pretende fazer e o que se faz na prática, tanto que se pode compreender o currículo como um processo: o currículo prescrito (o que foi aprovado); o planejado (originado de manuais, guias, ementas); o organizado (recursos educacionais, infraestrutura, apoio administrativo); o concreto (o que acontece na prática) e o currículo avaliado (revelador do que é na verdade valorizado no processo de ensino-aprendizagem).

Na pesquisa aqui apresentada, embora - como mostram os relatos - não seja um consenso entre todos os entrevistados, nem consciente por parte dos que admitiram haver um descompasso entre proposta teórica, estruturação curricular e conteúdo efetivamente ministrado, existe, como apontado por Feuerwerker (2002) e Souza (2010), uma diferença entre o currículo prescrito, planejado, organizado, concreto e o avaliado.

Embora o PPP do curso ainda apresente fragilidades - como a estrutura curricular em grade, a distância entre o ciclo básico e o profissionalizante e, consequentemente, entre teoria e prática, a dificuldade natural em se adotarem formas e metodologias alternativas de estruturar o ensino, o perfil do egresso delineado de modo que a estrutura curricular não contempla a formação, devido à forte concentração nas especialidades -, ressalta-se que muitos passos já foram percorridos, dado que o longo processo aqui relatado proporcionou a conscientização e a dessensibilização da comunidade acadêmica sobre as mudanças, a definição de eixos curriculares, o oferecimento de disciplinas em formatos diferenciados e de maneira mais integrada, a formação de parte dos docentes em pedagogia universitária - o que demonstra que o curso está pronto para as novas reformulações necessárias para sanar tais fragilidades.

Souza (2010), na pesquisa em que estudou as escolas médicas que implementaram mudanças curriculares, detectou características dos cursos que se propunham a realizar mudanças, sendo que a maioria das instituições de ensino demonstrou 
que o modelo de currículo anterior à decisão de mudança evidenciava um certo potencial com histórico de iniciativas de modificação recente e que todas apresentavam uma decisão quase consensual quanto à necessidade de superação do modelo curricular anterior. Ambas as características se encontram no Curso de Fonoaudiologia da FOB-USP, o que habilita o início de uma nova reestruturação.

No Brasil, muitos cursos na área de saúde vêm promovendo mudanças curriculares por revolução, ao implementarem modificações estruturais nos cursos e implantarem o currículo integrado. No entanto, Anastasiou (2001) e Anastasiou e Alves (2009) mencionam que as mudanças curriculares podem ocorrer por revolução ou por aproximações sucessivas, sendo que o curso de Fonoaudiologia da FOB-USP está se modificando por aproximações sucessivas, conforme se pode perceber pelos relatos apresentados neste artigo.

Como um PPP é sempre um processo em construção, novas mudanças e adaptações são e sempre serão necessárias, e os membros que se envolvem no processo estão sujeitos às vicissitudes da sua implantação e implementação, assim como de quem o operacionalizará (docentes e discentes), das possibilidades dos campos de prática, das limitações institucionais e de outras demandas que podem surgir. Portanto, todos conviverão com incertezas, desafios, paradoxos e contradições ao longo do processo (PÜSCHEL, 2011) e não haverá evolução se estes não forem enfrentados.

As conquistas já implantadas serão a base de apoio para as novas mudanças, mas a abertura da mente - que se caracteriza pela receptividade às várias informações provenientes de fontes diversificadas, pela mudança de paradigma, pela disponibilidade interna, pela capacidade de aceitar possíveis rotas alternativas e pelo reconhecimento da possibilidade de errar e recomeçar - deverá ser permanente, assim como o entusiasmo como atitude de reunir interesse, atenção e esforço.

\section{Notas}

$1 \mathrm{O}$ site da QSR International (http://www. qsrinternational.com) apresenta informações adicionais sobre as funcionalidades e as formas de aquisição do NVivo.

\section{Referências Bibliográficas}

ANASTASIOU, L. G. C. "Metodologia de Ensino na Universidade Brasileira: Elementos de uma Trajetória". In: CASTANHO, S. \& CASTANHO, M. E. (orgs.). Temas e Textos da Educação Superior. Campinas: Papirus, 2001.

\& ALVES, L. P. (orgs). Processos de Ensinagem na Universidade: Pressupostos para Estratégias de Trabalho na Sala de Aula. 3. ed. Joinville, SC: Univille, 2009.

BARDIN, L. Análise de Conteúdo. 4. ed. Lisboa: Edições 70, 2010.

BECK, C. L. C. et al. "Participação na Construção de um Projeto Político-Pedagógico na Enfermagem". Rev Bras Enferm, Brasília, DF, vol. 56, n. 4, jul./ago. 2003, pp. 405-408.

BRAID, L. M. G.; MACHADO, M. F. A. S. \& ARANHA, A. C. "Estado da Arte das Pesquisas sobre Currículo em Cursos de Formação de Profissionais da Área da Saúde: um Levantamento a Partir de Artigos Publicados entre 2005 e 2011". Interface, Botucatu, vol. 16, n. 42, jul./set. 2012, pp. 679-92.

BRASIL. "Lei n. 9394, de 20 de dezembro de 1996. Estabelece as Diretrizes e Bases da Educação Nacional". Diário Oficial [da] República Federativa do Brasil, Brasília, DF, 23 dez. 1996.

CARVALHO FILHO, G. J. Entre a Teoria e a Prática: o Projeto Político-Pedagógico do Curso de Medicina da UFMA. Tese (Doutorado em Educação), Faculdade de Filosofia e Ciências, Universidade Estadual Paulista, Marília, 2011.

FEUERWERKER, L. C. M. "Educação na Saúde: Educação dos Profissionais de Saúde - um Campo de Saber e de Práticas Sociais em Construção". Rev. Bras. Educ. Med., vol. 31, n. 1, 2007, pp. 3-4.

Mudanças na Educação Médica: os Casos de Londrina e Marília. Tese (Doutorado em Saúde Pública), Faculdade de Saúde Pública, Universidade de São Paulo, São Paulo, 2002.

FREITAS, M. C.; GUEDES, M. V.; SILVA, L. F. "Curso de Enfermagem da Universidade Estadual do Ceará: a História e o Projeto Político-Pedagógico Atual". Rev. Bras. Enferm., Brasília, DF, vol. 56, n. 4, jul./ago. 2003, pp. 385-387.

LAGE, M. C. "Utilização do Software NVivo em Pesquisa Qualitativa: uma Experiência em EaD”. ETD - Educ. Tem. Dig, Campinas, vol. 12, n. esp., mar. 2011, pp. 198-226.

LOPES-HERRERA, S.A. Análise do Projeto PolíticoPedagógico do Curso de Fonoaudiologia da FOB-USP: Analisando o Passado e o Presente para Definir o Futuro. Tese 
de livre-docência. Faculdade de Odontologia de Bauru. Universidade de São Paulo, 2014.

MANZINI, E.J. A Entrevista como Instrumento de Pesquisa em Educaşão e Educaşão Especial: Uso e Processo de Análise. Tese (Livre-Docência em Educação), Universidade Estadual Paulista "Júlio de Mesquita Filho" - Unesp, Campus Marília, 2008.

MINAYO, M. C. S. O Desafio do Conhecimento: Pesquisa Qualitativa em Saúde. 9. ed. São Paulo: Hucitec, 2006.

NÓBREGA-THERRIEN, S. M.; GUERREIRO, M. das G. da S.; MOREIRA, T. M. M.; ALMEIDA, M. I. de. "Projeto Político-Pedagógico: Concepção, Construção e Avaliação na Enfermagem". Revista da Escola da Enfermagem da USP, vol. 44, n.3, 2010, pp. 679-686.

OLIVEIRA, B. R. G. de; SCHNEIDER, J. F.; RIZOTTO, M. L. F.; RODRIGUES, R. M. "Avaliação e Construção de um Projeto Político-Pedagógico para a Graduação em Enfermagem". Rev. Bras. Enferm., Brasília, DF, vol. 56, n. 4, jul./ago. 2003, pp. 369-373.

OLIVEIRA, D. C. "Análise de Conteúdo TemáticoCategorial: uma Proposta de Sistematização". Rev. Enferm. Uerj, Rio de Janeiro, vol. 16, n. 4, out./dez. 2008, pp. 569-576.

OLIVEIRA, M. E. N. O Processo de Reestruturação Curricular do Curso de Pedagogia da Unesp - Marilia: Desafios e Possibilidades. Dissertação (Mestrado em Educação), Universidade Estadual Paulista, Faculdade de Filosofia e Ciências, Marília, 2011.

PÜSCHEL, V. A. A. A Mudansa Curricular do Bacharelado em Enfermagem da Escola de Enfermagem da USP: Análise Documental e Vivência dos Participantes. Tese (LivreDocência), Escola de Enfermagem, Universidade de São Paulo, São Paulo, 2011.

SANTOS, L. A. S. et al. "Projeto Pedagógico do
Programa de Graduação em Nutrição da Escola de Nutrição da Universidade Federal da Bahia: uma Proposta em Construção". Rev. Nutr., Campinas, vol. 18, n. 1, jan./fev. 2005, pp. 105-117.

SANTOS, S. S. G. "Perfil de Egresso de Curso de Enfermagem nas Diretrizes Curriculares Nacionais: uma Aproximação". Rev. Bras. Enferm., Brasília, DF, vol. 59, n. 2, mar./abr. 2006, pp. 217-221.

SIGNORELLI, M. C. et al. "Um Projeto Pedagógico de Graduação em Fisioterapia Pautado em Três Eixos Curriculares". Fisioter. Mov., Curitiba, vol. 23, n. 2, abr./ jun. 2010, pp. 331-340.

SILVERMAN, D. "Collecting Your Data". In: . Doing Qualitative Research. 3rd ed. Los Angeles:

Sage Publications, 2010a, cap. 12, pp. 189-217.

$$
\text { "Developing Data Analysis". In: }
$$

Doing Qualitative Research. 3rd ed. Los Angeles: Sage Publications, 2010b, cap.13, pp. 251-267.

. "Using Computers to Analysis Qualitative Data". In: _. Doing Qualitative Research. 3rd ed. Los Angeles: Sage Publications, 2010c, cap. 14, pp. 218-250.

SOUZA, P. A. Repercussões do Programa de Incentivo às Mudancas Curriculares nos Cursos de Medicina (Promed) nas Escolas Médicas. Tese (Doutorado em Saúde da Criança e do Adolescente), Faculdade de Ciências Médicas, Universidade Estadual de Campinas, Campinas, 2010.

UNIVERSIDADE DE SÃO PAULO. Campus Bauru. Projeto Político-Pedagógico do Curso de Graduação em Fonoaudiologia da Faculdade de Odontologia de Bauru, 2012b.

UNIVERSIDADE DE SÃO PAULO. Campus Bauru. Projeto Político-Pedagógico do Curso de Graduação em Fonoaudiologia da Faculdade de Odontologia de Bauru. 2014c. 